\title{
연구논문
}

\author{
통계모형을 활용한 박새류의 서식지 연결성 평가: \\ 서울시 도시생태현황도 자료를 중심으로 \\ 송원경* · 김은영** · 이동근*** \\ *수원시정연구원, **한국환경정책 · 평가연구원, ***서울대학교 조경 - 지역시스템공학부 \\ (2013년 4월 11일 접수, 2013년 5월 2일 승인)
}

\section{Habitat Connectivity Assessment of Tits Using a Statistical Modeling: Focused on Biotop Map of Seoul, South Korea}

\author{
Song, Wonkyong* $\cdot$ Kim, Eunyoung** $\cdot$ Lee, Dongkun*** \\ *Suwon Research Institute, **Korea Environment Institute \\ **Department of Landscape Architecture and Rural System Engineering, Seoul National University \\ (Manuscript received 11 April 2013; accepted 2 May 2013)
}

\begin{abstract}
Species distribution modeling is one of the most effective habitat analysis methods for wildlife conservation. This study was for evaluating the suitability of species distribution to distance between forest patches in Seoul city using tits. We analyzed the distribution of the four species of tits: varied tit (Parus varius), marsh tit (P. palustris), great tit (P. major) and coal tit (P. ater), using the landscape indexes and connectivity indexes, and compared the resulting suitability indexes from $100 \mathrm{~m}$ to $1,000 \mathrm{~m}$. As factors affecting to the distribution of tits, we calculated landscape indices by separating them into intra-patch indices (i.e. logged patch area (PA), area-weighted mean patch shape index (PSI), tree rate (TR)) and inter-patch indices (i.e. patch degree (PD), patch betweenness $(\mathrm{PB})$, difference probability of connectivity (DPC)), to analyze the internal properties of the patches and their connectivity by tits occurrence data using logistic regression modeling. The models were evaluated by AICc (Akaike Information Criteria with a correction for finite sample sizes) and AUC (Area Under Curve of ROC). The results of AICc and AUC showed DPC, PA, PSI, and TR were important factors of the habitat models for great tit and marsh tit at the level of distance $500 \sim 800 \mathrm{~m}$. In contrast, habitat models for coal tit and varied tit, which are known as forest interior species, reflected PA, PSI, and TR as intra-patch indices rather than connectivity. These mean that coal tit and varied tit are more likely to find a large circular forest patch than a small and long-shaped forest patch, which are higher rate of forest. Therefore, different strategies are required in order to
\end{abstract}

Corresponding Author: Eunyoung Kim, Korea Environment Institute, 215 Jinheungno, Eunpyeong-gu, Seoul 122-706, Korea Tel: +82-26922-7800 E-mail: eykim@kei.re.kr 
enhance the habitats of the forest birds, tits, in a region that has fragmented forest patches such as Seoul city. It is important to manage forest interior areas for coal tit and varied tit, which are known as forest interior species and to manage not only forest interior areas but also connectivity of the forest patches in the threshold distance for great tit and marsh tit as adapted species to the urban ecosystem for sustainable ecosystem management.

Keywords : Probability of Connectivity, Logistic Regression, Patch Area, Habitat Suitability Assessment, Threshold Distance

\section{I. 서 론}

서울시는 급격한 개발로 인해 녹지가 단절되고 파편화되어 단기간에 큰 생태계 변화를 경험하였 다. 토지피복지도를 통해 1980년대 이후 토지피복 변화를 분석한 결과 약 20 년 동안 전체 서울시 녹지 면적이 약 $8 \%\left(12.6 \mathrm{~km}^{2}\right)$ 정도가 훼손된 것으로 파 악되었다. 이러한 변화는 녹지 패치의 크기를 감소 시키고 패치간 거리를 증가시켜 야생동 · 식물의 서 식에 큰 영향을 미치게 된다(Turner, 1989; Hanski, 1999). 특히 도시지역과 같이 고립된 녹지패치를 서 식지로 이용하고 있는 야생동물은 그 영향이 더욱 심각하게 나타날 수 있다. 따라서 서식지가 단절된 경관에서 야생동물의 이동성을 고려한 연결성 평가 는 개체군 보전에 중요한 화두로 떠오르고 있다 (Hanski, 1998). 이러한 관점에서 서울시 녹지의 서식지 기능을 제대로 분석하기 위해서는 현재 서 울시 녹지 면적이 전체 면적의 약 $24 \%$ 를 차지하고 있다는 일차원적인 평가보다 녹지의 분포 패턴을 파악하고 이에 따른 연결성을 평가할 수 있는 방법 론 도입이 필요한 실정이다.

연결성의 개념은 Levins(1969) 이후, 1970년대 경관의 공간적 구조가 개체군의 역동성에 영향을 준다는 패치 기반의 개체군 모델에 근거하여 발전 하였다(Turner, 2005; Angold et al., 2006). 이 러한 연구들을 토대로 서식지 패치 사이에서 일어 나는 야생동 - 식물의 이동은 단순히 개체의 특성뿐 만 아니라 주변 경관 속성에 영향을 받는다는 사실 이 일반화된 개념으로 받아들여지면서, 경관 연결 성이라는 용어가 사용되었다(Tischendorf and Fahrig, 2000; 송원경, 2012). 경관 연결성은 종
공급원 패치 사이에서 이동을 용이하게 하거나 방 해하는 경관의 수준(Taylor et al. 1993)으로 정의 된다. 이는 경관의 구조적 특성으로 인해 개체 혹은 유전자 흐름이 기능적으로 영향을 받게 된다는 것 을 의미한다. 따라서 경관 연결성을 이해하는 것은 지역의 생물종 서식 환경을 파악하는데 중요한 요 인이 될 수 있다.

이처럼 연결성의 개념이 일반화되기 시작하면서 경관 연결성을 유지하는 것이 야생동물 서식환경을 보전 · 관리하는데 중요한 역할을 한다는 다양한 연 구가 발표되고, 여러 보전 계획에 적용되고 있다 (Luque et al. 2012). 이러한 연구들은 경관 연결 성과 야생동 - 식물 출현 및 서식에 대한 정량적 분 석을 바탕으로 경관 연결성의 중요성을 고찰하고 있다. 그러나 경관 메트릭스 및 대상종의 특성에 따 라 연결성은 다양하게 측정될 수 있으므로 목표종 에 대한 경관 연결성을 측정하는 것이 일반적이다.

본 연구에서는 다양한 녹지 패치 연결 수준에 따 른 박새과 4종의 서식가능성을 정량적으로 파악하 기 위해 종별 서식에 영향을 미치는 요인을 분석하 고, 연결성 향상을 위한 임계거리를 제시하고자 한 다. 즉, 현재 녹지 분포 및 연결 수준을 분석하여 어 느 수준의 서식지 단절이 박새류의 서식지 분포에 중요한 영향을 줄 수 있는지를 파악함으로서 보다 계획적인 녹지 관리의 가능성을 열어줄 수 있다. 이 러한 분석 결과는 도시지역의 녹지조성 및 관리시 최소 연결녹지의 설치 지역 선정 시 참고자료로 활 용될 뿐만 아니라 지속적인 생태계 관리에 기여할 것이다. 


\section{II. 연구의 범위 및 방법}

\section{1. 연구 대상지}

본 연구 대상지는 우리나라에서 가장 시가화율이 높은 도시 중 하나인 서울시를 선정하였다 $\left(37^{\circ} 34\right.$ $\left.\mathrm{N}, 126^{\circ} 59^{\prime} \mathrm{E}\right)$. 서울시는 약 $605 \mathrm{~km}^{2}$ 면적, 동서 $36.8 \mathrm{~km}$, 남북 $30.3 \mathrm{~km}$ 의 크기이며, 주변에 북한산 $(836 \mathrm{~m})$, 도봉산 $(740 \mathrm{~m})$, 관악산 $(629 \mathrm{~m})$ 등 높은 산 림과 남산 $(265 \mathrm{~m})$ 등 도심 내부 산림을 보유하여 다 양한 야생동물이 서식하고 있다. 그러나 그 동안 급 속한 도시개발 과정에서 많은 산림 녹지가 파편화 되어 야생동물 서식지가 급속히 단절이 진행되어왔 다(송원경 등, 2012). 특히 대부분의 녹지가 도시 외곽에 분포하고 있어(강완모와 박찬열, 2011), 도 시공원 등과 같은 내부 녹지는 도시화지역에 둘러 싸인 섬 형태로 존재한다(Figure 1).

\section{2. 대상종 및 분석자료}

박새류는 참새목 박새과에 속한 조류로 구북구 일원에서 남쪽으로 자바섬까지 분포하고 있으며, 아 무르강 유역, 우수리 지역, 중국 북부와 서북부, 사 할린, 한반도 전역과 주변 도서 지역에도 분포하고 있다(원병오, 1981). 한반도에 서식하는 박새류로는 곤줄박이(Parus varius), 쇠박새(P. palustris), 북
방쇠박새(P. montanus), 진박새(P. ater), 박새(P. major) 등 5 종이 기록되어 있으며(임신재 등, 2011), 이 중 곤줄박이, 쇠박새, 진박새, 박새는 우리나라 전역에서 번식하는 흔한 텃새로서(이우신 등, 2000), 서울시에서도 흔히 발견되는 산림성 조류이다. 이 들 박새류는 산림에 서식하는 대표적인 식충성 조 류로 산림생태계의 건전성 유지 등에 중요한 역할 을 수행한다(이우신 등, 2010). 국내에서는 수종에 따른 박새류 채이 특성 연구(박찬열, 2001), 도시림 식생유형별 박새과 출현 특성 연구(홍석환과 곽정 인, 2011), 침엽수림과 활염수림 지역에서의 박새 류 인공새집 이용 특성 연구(임신재 등, 2008; 2011) 등 박새과의 서식환경에 대한 연구가 일부 진행되 었다.

서울시는 급격한 도시환경 변화에 대응하고 현존 하는 자연생태계를 보전 · 관리하고자 1999년 이후 비오톱 현장조사를 진행하여 도시생태현황도를 구 축하였다(서울특별시, 2010). 서울시 도시생태현황 도는 토지피복, 토지이용, 현존식생 등을 이용하여 토지를 주거지 비오톱, 조경녹지 비오톱, 산림지 비 오톱 등으로 구분하고 있다(서울특별시, 2010). 본 연구에서는 이렇게 구축된 비오톱 유형도를 바탕으 로 산림녹지와 조경녹지, 과수원 등 녹지지역을 추 출하여 도시녹지로 재분류하였다. 분류된 도시녹지

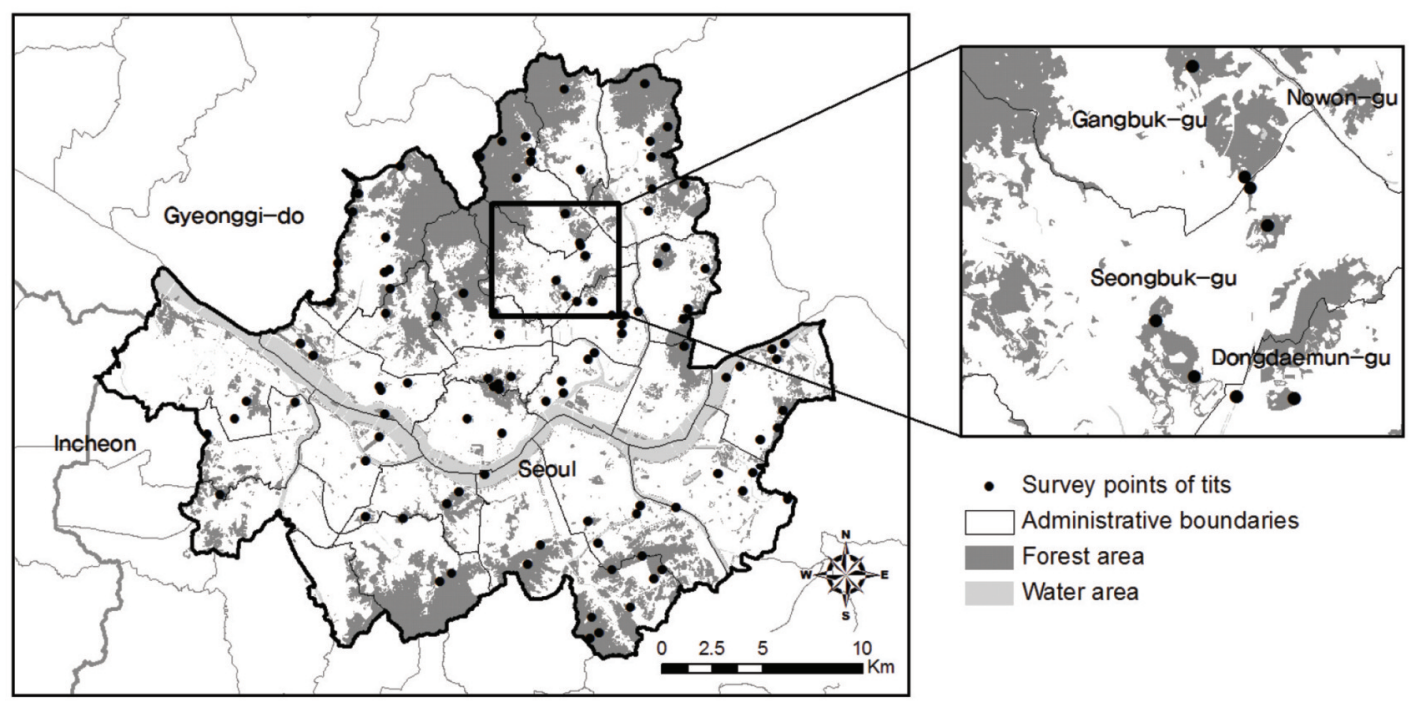

Figure 1. Study area and survey points 
는 패치 단위로 통합하여 기초 분석 자료를 구축하 였다. 서울시 비오톱유형도는 식생유형의 경우 최 소 $100 \mathrm{~m}^{2}$ 단위로 유형을 구분하고 있으나, $50 \mathrm{~m}^{2}$ $100 \mathrm{~m}^{2}$ 면적의 녹지패치가 다수 분포하고 있으므로 본 연구에서는 $50 \mathrm{~m}^{2}$ 이상의 녹지패치를 최소 분석 단위로 활용하였다. 서울특별시(2010)에서는 각 구 별 주요 산림 및 도시공원을 중심으로 130 개 조사 지점을 선정하여 선조사방법과 정점조사방법을 혼 용한 현장조사를 실시하고, 이와 함께 2000년부터 2008년까지 진행된 생태조사 연구보고서를 통해 서울시에 출현한 조류 목록 및 지점을 조류분포도 로 구축하여 제공하고 있다. 본 연구에서는 서울특 별시(2010) 조사자료를 이용하여 조류조사 자료가 기입된 포인트를 녹지패치에 대응시켜 106 개 녹지 패치에서 조류종이 조사된 것을 확인하였다. 이 중 박새과 4종의 분포가 확인된 67 개 지점 정보를 추 출하여 박새과 출현정보로, 그 외 패치를 비출현 정 보로 구분하여 분석에 이용하였다(Figure 1). 106 개 지점 중 $0.01 \mathrm{~km}^{2}$ 이하의 녹지패치가 16 개, $0.01 \sim 0.1 \mathrm{~km}^{2}$ 녹지패치가 35 개, $0.1 \sim 1 \mathrm{~km}^{2}$ 녹지패 치가 38 개, $1 \mathrm{~km}^{2}$ 이상이 17 개로 확인되었으며, 박 새과가 출현한 67 개 녹지패치는 $0.01 \mathrm{~km}^{2}$ 이하가 9 개, $0.01 \sim 0.1 \mathrm{~km}^{2}$ 가 16 개, $0.1 \sim 1 \mathrm{~km}^{2}$ 가 26개, $1 \mathrm{~km}^{2}$
이상이 16 개로 확인되었다. 따라서 박새류는 넓은 산림지역에서 출현확률이 높은 것으로 나타났다.

\section{3. 경관 지수 계산}

박새류 분포에 영향을 미치는 요인으로서 본 연 구에서는 크게 패치 내부적인 속성과 외부적인 속 성을 구분하여 지수를 계산하였다(Table 1). 이는 경관생태학 및 생태공학적 관점에서 입지 포텐셜 및 공급 포텐셜로 해석될 수 있다. 즉, 패치 자체의 서식지 제공 능력 및 잠재적인 종 공급 능력을 종합 적으로 평가하기 위해 패치 내부적 속성과 외부적인 속성을 함께 고려할 필요가 있다. 패치 내부적인 속 성은 패치 그 자체의 서식지 특성을 의미하는 지수 로서 패치면적(patch area: PA), 면적 가중 형태지수 (area-weighted mean patch shape index: PSI), 교목식생지역 비율(tree ratio: TR), 패치 외부적 인 속성으로는 패치 연결차수(patch degree: PD), 패치 매개성(patch betweenness: PB), 패치 연결 가 능성 지수(difference of probability of connectivity: $\mathrm{DPC}$ 를 선정하였다(Table 1). PA는 서식지로서의 패 치 속성을 설명하는 가장 대표적인 지수로서(Forman, 1995), 넓은 면적일수록 서식가능성이 높아지는 것 으로 알려져 있다(Ferraz et al., 2007). PSI는 패치

Table 1. Summary of selected patch metrics in the models

\begin{tabular}{|c|c|c|c|}
\hline Factor name & Description & & Formula and abbreviation \\
\hline PA & Logged patch area $(\log )$ & $P A=\log \left(a_{i}\right)$ & $\begin{array}{l}\mathrm{a}_{\mathrm{i}}=\text { the area of patch } \mathrm{i} \\
\text { (Forman and Godron, 1986) }\end{array}$ \\
\hline PSI & $\begin{array}{l}\text { Area-weighted mean patch } \\
\text { shape index }\end{array}$ & $P A=\min L_{i} / L_{i}$ & $\begin{array}{l}\mathrm{L}_{\mathrm{i}}=\text { the perimeter of patch } \mathrm{i} \\
\operatorname{minL}_{\mathrm{i}}=\text { the minimum perimeter having the area of patch } \mathrm{i} \\
(\text { Forman and Godron, 1986) }\end{array}$ \\
\hline TR & Tree ratio in a patch & $T R=T_{a} / P_{a}$ & $\begin{array}{l}\mathrm{T}_{\mathrm{a}}=\text { the area of tree in patch } \mathrm{i} \\
\mathrm{P}_{\mathrm{a}}=\text { the area of patch } \mathrm{i}\end{array}$ \\
\hline PD & $\begin{array}{c}\text { The number of its adjacent } \\
\text { edges }\end{array}$ & $P D=\sum_{i=1}^{n} a\left(P_{i}, P_{j}\right)$ & $\begin{array}{l}\mathrm{n}=\text { total number of patches } \mathrm{a}(\mathrm{Pi}, \mathrm{Pj})=1 \text { if patches } \mathrm{Pi} \text { and } \mathrm{Pj} \text { are } \\
\text { connected in the threshold distance, } 0 \text { otherwise(Freeman, 1979) }\end{array}$ \\
\hline $\mathrm{PB}$ & $\begin{array}{c}\text { The number of shortest } \\
\text { paths going through a patch }\end{array}$ & $P B=\sum_{i \neq j, i \neq v, j \neq v} \frac{g_{i v j}}{g_{i v}}$ & $\begin{array}{l}\mathrm{g}_{\mathrm{ivj}}=\text { the number of geodesic linking patches } \mathrm{i} \text { and } \mathrm{j} \text { that contain } \mathrm{v} \\
\mathrm{g}_{\mathrm{ij}}=\text { the number of geodesic paths from patches } \mathrm{i} \text { to } \mathrm{j} \text { (Freeman, 1979) }\end{array}$ \\
\hline DPC & $\begin{array}{l}\text { Difference of connectivity } \\
\text { probability }\end{array}$ & $\begin{array}{l}P C=\frac{\sum_{i=1}^{n} \sum_{j=1}^{n} a_{i} \cdot a_{j} \cdot p^{* i j}}{A_{L}^{2}} \\
D P C=\frac{P C-P C_{\text {remove }-i}}{P C}\end{array}$ & $\begin{array}{l}n=\text { total number of patches } \\
\mathrm{a}_{\mathrm{i}}, \mathrm{a}_{\mathrm{j}}=\text { the sizes of patches } \mathrm{i} \text { and } \mathrm{j} \\
\mathrm{A}_{\mathrm{L}}=\text { the total landscape area } \\
\mathrm{P}_{\mathrm{ij}}=\text { the maximum product probability of all possible paths between } \\
\quad \text { patches } \mathrm{i} \text { and } \mathrm{j} \\
\mathrm{P}_{\text {remove- }}=\text { the overall index value after the removal of that single patch } \mathrm{i} \\
\text { (Saura and Pascual-Hortal, 2007) }\end{array}$ \\
\hline
\end{tabular}


면적과 함께 대표적인 경관생태지수로서(Forman, 1995), 형태지수가 작을수록 원에 가까운 형태임을 의미한다. 이 지수는 가장자리 및 내부지역 면적 비 율과 밀접한 관계가 있으므로 패치간 이동 및 야생 동물 서식에 영향을 미친다(Collinge and Palmer, 2002). TR은 박새과가 우리나라의 대표적인 산림 성 조류로서 나무구멍 등을 둥지로 이용하기 때문에 (임신재 등, 2011) 지수에 포함되었다. 연결성 지수 중 $\mathrm{PD}$ 와 $\mathrm{PB}$ 는 그래프 이론에 기초한 대표적인 구조 적 연결성 측정 방법으로서(Freeman, 1979), $\mathrm{PD}$ 는 해당 패치에 임계거리 이내의 거리로 연결된 패치의 수를 의미한다(Jordán et al., 2003). PB는 연결된 패 치 중 해당 패치를 통과하는 정도를 의미하며, 연결 성을 유지하기 위한 징검다리 녹지를 파악하는데 유 리하다(Minor and Urban, 2007; 송원경 등, 2012). $\mathrm{DPC}$ 는 경관 전체의 연결성을 유지하기 위해 고안된 지수로서(Saura and Pascual-Hortal, 2007), 확 산 가능성을 고려하여 연결성을 측정하는 방법이다. 패치간 거리는 각 패치 경계로부터의 최단거리로서, ArcGIS 9.3(ESRI Inc. USA) 프로그램을 이용하여 측정하였다.

\section{4. 연결거리별 서식지 모형 평가}

박새류 중 비교적 서식지 특성 및 이동거리에 관 련된 연구가 많이 진행된 박새의 경우 이동거리는 지역적 특성과 계절, 암수 등에 따라 다르게 나타난 다고 알려져 있다(Krebs, 1972). 박새의 이소거리 를 측정한 Dhondt(1979)는 수컷의 80\%가 산란된 둥지의 $510 \mathrm{~m}$ 이내, 암컷의 $80 \%$ 가 $900 \mathrm{~m}$ 이내의 거리에서 발견됨을 확인하였다. 이러한 이소거리는 계절에 따라 다르지만, 평균 30 192m 정도인 것 으로 분석되었다. Verhulst et al.(1997)은 이소지 역으로부터 짝짓기 둥지까지 거리를 측정하였는데 약 $40 \%$ 의 박새가 $500 \mathrm{~m}$ 이내 거리에서 둥지를 트는 것으로 확인되었다. Dingemanse et al.(2003)은 인공새집을 이용하여 이소한 박새의 확산 거리를 분석한 결과 암컷 $(643 \pm 376 \mathrm{~m})$ 이 수컷 $(498 \pm 310 \mathrm{~m})$ 보다 확산거리가 더 긴 것으로 나타났다. Matthysen et al.(2005) 역시 인공새집을 이용한 박새의 확산 거리를 측정한 결과 약 500 800m 정도인 것으로 분석되었다. 이에 비해 비교적 동질적인 식생 경관 지역에서 분석된 박새의 확산 거리 연구에서는 전 체의 $92 \%$ 가 $200 \mathrm{~m}$ 이내의 거리에 있는 인공새집을 선택하였다(Andreu and Barba, 2006). 우리나라 에서는 박새의 확산 및 이동거리에 대한 연구는 미 흡한 실정으로 국외 사례를 통해 종합해 본 박새의 이동거리는 평균 $900 \mathrm{~m}$ 이내의 거리에서 지역에 따 라 매우 다양하게 나타났다. 따라서 본 연구에서는 $100 \sim 1,000 \mathrm{~m}$ 까지 $100 \mathrm{~m}$ 거리 간격으로 패치간 연 결 거리를 다르게 설정하여 연결 거리에 따른 서식 지 평가시 민감성을 평가하였다.

패치 내부적인 속성을 나타내는 PA, PSI, TR과 연결 거리에 따라 영향을 받는 연결성 지수 $\mathrm{PD}$, $\mathrm{PB}, \mathrm{DPC}$ 를 거리별로 측정하여 각각의 거리별 서 식지 평가를 실시하였다. 패치 및 거리별로 계산된 6 개 지수를 이용하여 서울시 조류분포도를 통해 추 출된 박새류 발견지점과 비발견지점에 따른 서식지 이용확률을 계산하기 위해 로지스틱 회귀분석을 실 시하였다. 로지스틱 회귀분석은 출현/비출현 정보 와 같은 이분법적 정보를 활용하여 환경변수를 통 계적으로 해석할 수 있는 효과적인 방법론으로서 본 연구에서 활용한 종조사 자료에 적합한 방법론 이다. 로지스틱 회귀분석 결과 중에서 최적 모형 선 정을 위해 적은 샘플 사이즈에 적용될 수 있는 수정 된 Akaike 정보량(AICc) 값을 이용하였으며, 거리 별 최적 모형별 예측 확률을 비교하여 임계거리를 증가함에 따라 예측 확률이 어떻게 변화하는지 파 악하였다(수식 1). AICc 값의 변화는 단순히 우도에 의한 모형 선택보다 모형에 포함된 변수 개수를 모 형 선택에 적용함으로써 최적 모형을 선택할 수 있 는 장점을 가지고 있다. 특히 $\mathrm{AICc}$ 는 적은 샘플 사 이즈의 분석에 효과적인 것으로 알려져 있다 (Amano et al., 2008).

$A I C_{c}=-2(\log -$ likelihood $)+2 K+\frac{2 \mathrm{~K}(\mathrm{~K}+1)}{n-K-1}$ Formula 1

여기서, $\mathrm{K}$ 는 모형에 포함된 변수 개수, $\mathrm{n}$ 은 샘플 수를 의미한다. 거리별 서식지 모형의 예측확률을 비 
교함으로써 서울시에 분포하고 있는 박새류의 분포를 가장 잘 설명할 수 있는 임계거리를 파악하였다. 이와 함께 ROC(Receiver Operating Characteristic)의 AUC(Area Under Curve)를 이용하여 모델의 적 합도를 평가하였다. $\mathrm{AUC}$ 는 0.5 에서 1 사이의 값으 로 모형 적합도를 평가하여 모형 비교에 효과적이 다(Brotons et al., 2004). 이러한 분석 방법론을 거리별로 박새류 서식지 분석에 적용함으로써 서식 지 평가를 위한 임계거리를 파악하였다. 통계분석 은 R 2.15.1(R core team, 2012)를 이용하였다.

\section{III. 결과 및 고찰}

서울시 도시생태현황도를 통해 분석된 서울시 녹 지패치는 총 2,148 개로 확인되었다. 전체 녹지패치 를 대상으로 종 현황이 기록된 106 개 패치 중 67 개 녹지패치에서 박새류가 출현하였다. 그 중 박새는 60 개 녹지패치에서 출현하였으며, 출현지점의 최 소 녹지패치 면적은 $356 \mathrm{~m}^{2}$ 로 나타났다. 쇠박새의 경우 42 개 녹지패치에서 출현하였으며 발견된 최소 녹지패치 면적은 $4,730 \mathrm{~m}^{2}$ 으로 나타났다. 진박새와 곤줄박이는 각각 14 개, 21 개의 녹지패치에서 발견 되었으며, 두 종이 출현한 최소 녹지패치 면적은 $57,835 \mathrm{~m}^{2}$ 로 분석되었다. 종분포자료를 확인한 결 과, 진박새와 곤줄박이가 박새와 쇠박새보다 넓은 녹지패치를 선호하는 것으로 분석되었다(Figure 2). 박새류 출현에 따른 녹지패치 면적은 t-test 결 과 $\mathrm{p}<0.001$ 수준에서 유의한 것으로 확인되었다. 즉, 박새를 포함한 박새류는 넓은 산림, 원형에 가 까운 형태의 산림, 잘 연결된 산림지역을 선호하는
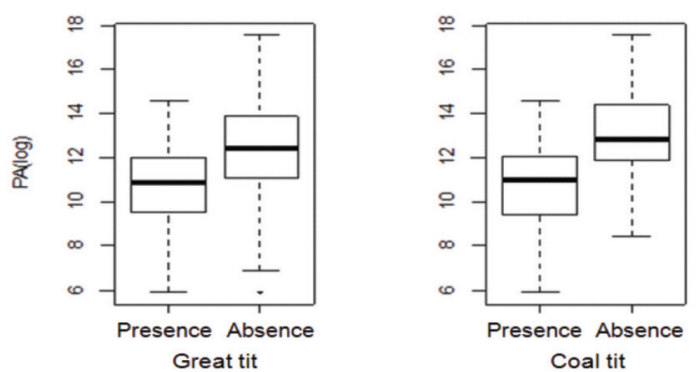

Figure 2. Boxplots to explain differences of patch areas by the tits' occurrence
것으로 분석되었다.

녹지패치간 연결거리에 대한 서식지 평가를 위해 거리별로 로지스틱 회귀분석을 실시한 결과 박새과 4 개 종의 서식지 모형은 모두 다르게 평가되었다. 박새는 임계거리 $100 \mathrm{~m}$ 를 제외한 모형에서 임계거 리가 증가함에 따라 모형의 적합도가 높아짐을 확인 할 수 있다(Table 2). 박새의 경우 $500 \mathrm{~m}$ 이상의 거 리에서 모형의 적합도가 특히 높아져 $800 \mathrm{~m}$ 거리에 서 가장 높은 모형 적합도를 보여주고 있다. 쇠박새 역시 임계거리 증가에 따라 모형의 적합도가 향상되 는 경향을 보이며, 특히 $500 \mathrm{~m}$ 이상의 거리에서 모 형의 적합도가 임계점에 다다름을 확인할 수 있다. 이는 박새와 쇠박새가 $500 \mathrm{~m}$ 내외의 거리에 분포한 녹지패치 연결성을 모형에 중요하게 반영하고 있기 때문인 것으로 해석된다. 박새와 쇠박새의 경우 분 포를 예측하는데 PSI와 DPC 변수가 대부분 선택되 었는데, 이는 인접 패치와의 거리와 임계거리 이내 에 위치한 패치의 면적이 중요하게 작용한다는 것을 의미한다. 특히 $\mathrm{DPC}$ 는 최근 다양한 연구를 통해 소 개되는 연결성 측정 방법론으로서, 대표적인 기능 적 연결성 측정 방법으로 알려져 있다(Luque et al. 2012). PSI 변수의 선정은 서울시의 녹지가 동일한 면적으로 분포하더라도 원형에 가까운 형태일 경우 더욱 박새의 출현 확률이 높아질 수 있다는 것을 의 미한다. 즉, 모든 모형에서 두 패치의 면적이 넓으 면서 박새류가 이동가능한 거리 이내에 위치하고, 해당 패치의 형태도 원형에 가까울수록 박새류의 서 식확률이 높아질 수 있다는 것을 의미한다.

이에 비해 진박새와 곤줄박이는 임계거리 증가에 따라 모형 적합도의 변화가 거의 없음을 확인할 수
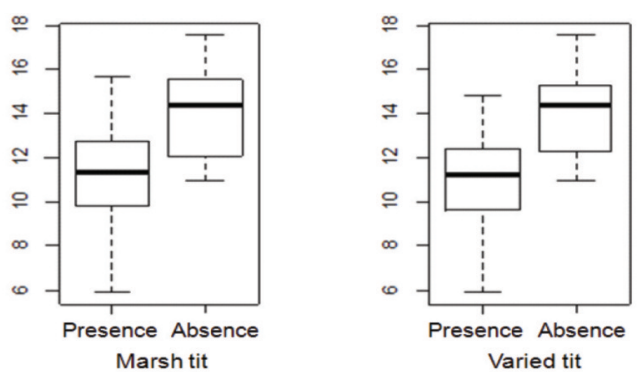
Table 2. Comparison of generalized linear models by distance

\begin{tabular}{|c|c|c|c|c|c|c|}
\hline Species & Distance & Model variables & $\mathrm{K}$ & $\mathrm{AICc}$ & LL & AUC \\
\hline \multirow{10}{*}{ Great tit } & $100 \mathrm{~m}$ & PA, PSI, PD100, DPC100 & 5 & 123.76 & -56.58 & 0.78 \\
\hline & $200 \mathrm{~m}$ & PSI, DPC200 & 3 & 127.06 & -60.41 & 0.73 \\
\hline & $300 \mathrm{~m}$ & PSI, DPC300 & 3 & 127.55 & -60.66 & 0.74 \\
\hline & $400 \mathrm{~m}$ & PSI, DPC400 & 3 & 125.22 & -59.49 & 0.75 \\
\hline & $500 \mathrm{~m}$ & PA, PSI, PB500, DPC500 & 4 & 123.86 & -57.73 & 0.78 \\
\hline & $600 \mathrm{~m}$ & PA, PSI, DPC600 & 4 & 122.04 & -56.82 & 0.79 \\
\hline & $700 \mathrm{~m}$ & PA, PSI, DPC700 & 4 & 121.02 & -56.31 & 0.79 \\
\hline & $800 \mathrm{~m}$ & TR, PB800, DPC800 & 4 & $115.70^{*}$ & -53.65 & 0.80 \\
\hline & $900 \mathrm{~m}$ & PA, PSI, DPC900 & 4 & 122.20 & -56.90 & 0.78 \\
\hline & $1,000 \mathrm{~m}$ & PA, PSI, TR, DPC1000 & 5 & 123.34 & -56.37 & 0.77 \\
\hline \multirow{10}{*}{ Marsh tit } & $100 \mathrm{~m}$ & PSI, DPC100 & 4 & 103.51 & -47.56 & 0.83 \\
\hline & $200 \mathrm{~m}$ & PSI, DPC200 & 3 & 102.12 & -47.94 & 0.83 \\
\hline & $300 \mathrm{~m}$ & PSI, TR, DPC300 & 4 & 100.46 & -46.03 & 0.85 \\
\hline & $400 \mathrm{~m}$ & PSI, DPC400 & 3 & 97.66 & -45.71 & 0.85 \\
\hline & $500 \mathrm{~m}$ & PSI, TR, DPC500 & 4 & 96.51 & -44.06 & 0.86 \\
\hline & $600 \mathrm{~m}$ & PSI, DPC600 & 3 & 96.04 & -44.90 & 0.86 \\
\hline & $700 \mathrm{~m}$ & PSI, DPC700 & 3 & $95.84 *$ & -44.80 & 0.85 \\
\hline & $800 \mathrm{~m}$ & PSI, DPC800 & 3 & 96.46 & -45.11 & 0.85 \\
\hline & $900 \mathrm{~m}$ & PSI, DPC900 & 3 & 98.03 & -45.90 & 0.85 \\
\hline & $1,000 \mathrm{~m}$ & PSI, DPC1000 & 3 & 98.87 & -46.32 & 0.85 \\
\hline \multirow{10}{*}{ Coal tit } & $100 \mathrm{~m}$ & PA, PSI, TR, PD100 & 5 & 60.35 & -24.88 & 0.90 \\
\hline & $200 \mathrm{~m}$ & PA, PSI, TR & 4 & 58.17 & -24.89 & 0.90 \\
\hline & $300 \mathrm{~m}$ & PA, PSI, TR, PD300 & 5 & 53.12* & -21.26 & 0.93 \\
\hline & $400 \mathrm{~m}$ & PA, PSI, TR & 4 & 58.17 & -24.89 & 0.90 \\
\hline & $500 \mathrm{~m}$ & PA, PSI, TR, PD500 & 5 & 57.53 & -23.47 & 0.92 \\
\hline & $600 \mathrm{~m}$ & PA, PSI, TR & 4 & 58.17 & -24.89 & 0.90 \\
\hline & $700 \mathrm{~m}$ & PA, PSI, TR & 4 & 58.17 & -24.89 & 0.90 \\
\hline & $800 \mathrm{~m}$ & PA, PSI, TR & 4 & 58.17 & -24.89 & 0.90 \\
\hline & $900 \mathrm{~m}$ & PA, PSI, TR, PB900 & 5 & 56.30 & -22.85 & 0.91 \\
\hline & $1,000 \mathrm{~m}$ & PA, PSI, TR, PB1000 & 5 & 56.34 & -22.87 & 0.91 \\
\hline \multirow{10}{*}{ Varied tit } & $100 \mathrm{~m}$ & PA, TR & 4 & 77.09 & -34.35 & 0.87 \\
\hline & $200 \mathrm{~m}$ & PA, TR, PD200 & 4 & 74.24 & -32.92 & 0.89 \\
\hline & $300 \mathrm{~m}$ & PA, TR & 3 & 74.96 & -34.36 & 0.87 \\
\hline & $400 \mathrm{~m}$ & PA, TR, PD400 & 4 & 73.71* & -32.65 & 0.88 \\
\hline & $500 \mathrm{~m}$ & PA, TR & 3 & 74.96 & -34.36 & 0.87 \\
\hline & $600 \mathrm{~m}$ & PA, TR, PD600 & 4 & 74.49 & -33.05 & 0.87 \\
\hline & $700 \mathrm{~m}$ & PA, TR & 3 & 74.96 & -34.36 & 0.87 \\
\hline & $800 \mathrm{~m}$ & PA, TR, PD800 & 4 & 74.91 & -33.26 & 0.87 \\
\hline & $900 \mathrm{~m}$ & PA, TR & 3 & 74.96 & -34.36 & 0.87 \\
\hline & $1,000 \mathrm{~m}$ & PA, TR, PD1000 & 4 & 74.56 & -33.08 & 0.88 \\
\hline
\end{tabular}

K: Number of variables, AICc: Corrected Akaike information criterion, LL: Log-likelihood, AUC: Area under curve, *: the optimized model

있다. 진박새는 임계거리 $300 \mathrm{~m}$ 에서, 곤줄박이는 $200 \mathrm{~m}$ 와 $400 \mathrm{~m}$ 에서 모형의 적합도가 가장 높은 것
으로 파악되었으나(Table 2), 임계거리 증가에 따 른 적합도 경향은 파악하기 어려웠다. 이는 진박새 


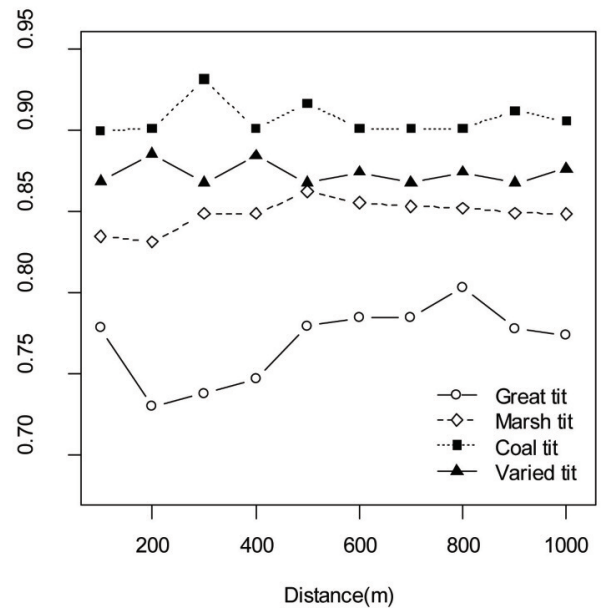

Figure 3. AUC changes of generalized linear models by distance

와 곤줄박이가 산림 내부를 선호하는 특징이 있는 만큼 패치 자체의 특성인 패치 면적, 면적 가중 형 태지수, 교목식생지역 면적 비율 등을 주로 모형에 포함시키는 것과 동일하게 해석할 수 있는 부분이 다. 즉, 진박새와 곤줄박이는 넓은 녹지패치, 원형 에 가까운 녹지패치 형태, 교목의 비율이 높은 지역 을 선호하며 주변 패치와의 연결성은 이에 비해 중 요도가 떨어짐을 확인할 수 있다. 이러한 차이는 박 새과의 종별 서식 특성의 차이를 보여주고 있다.

박새의 경우 임계거리 $800 \mathrm{~m}$ 에서 모형의 적합도 가 가장 높게 나타났지만, 전체적인 모형별 AUC 값 분포를 확인한 결과 박새와 쇠박새의 경우 임계거리 $500 \mathrm{~m}$ 이상의 지점에서 $\mathrm{AUC}$ 값이 급격히 높아짐 을 확인할 수 있다. 이는 박새와 쇠박새의 분포를 가 장 잘 설명할 수 있는 임계거리가 $500 \mathrm{~m}$ 이상의 거 리임을 의미한다(Figure 3). 또한 박새의 경우 임계 거리가 $800 \mathrm{~m}$, 쇠박새의 경우 $500 \mathrm{~m}$ 가 넘어갈 경우 오히려 모형의 적합도가 낮아지는 것을 확인할 수 있는데, 이는 서식지 모형을 구축할 때 이 거리를 초 과하는 연결녹지는 박새와 쇠박새의 서식환경 분석 에 영향을 주기 어려울 수 있다고 추정할 수 있다. 다만, 정확한 서식지 단절 수준을 파악하기 위해서 는 현장 실험을 통한 자료 수집이 요구된다.

종별로 최적 모형의 $\mathrm{ROC}$ 곡선을 확인해본 결과 진박새의 $\mathrm{AUC}$ 값이 임계거리 $300 \mathrm{~m}$ 에서 0.93 으 로 가장 높고, 곤줄박이 $(200 \mathrm{~m}, \mathrm{AUC}=0.89)$, 쇠박

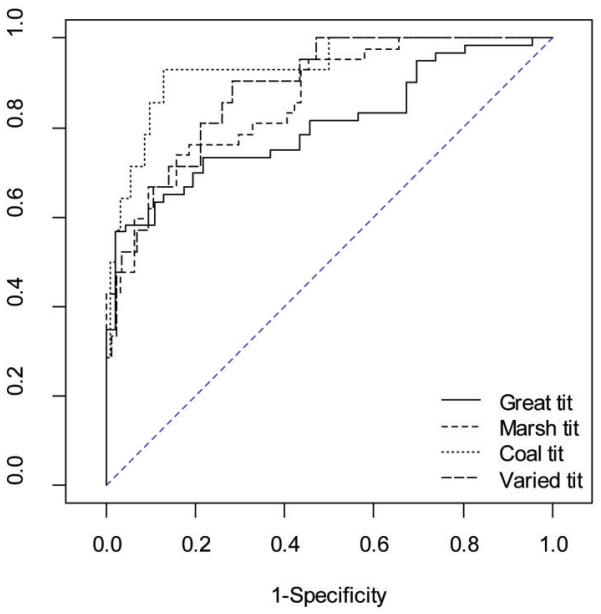

Figure 4. ROC curves of optimized models

새 $(500 \mathrm{~m}, \mathrm{AUC}=0.86)$, 박새 $(800 \mathrm{~m}, \mathrm{AUC}=0.80)$ 순으로 AUC 값이 분포함을 확인하였다(Figure 4). 이러한 결과는 산림 내부종인 진박새와 곤줄박이의 경우 서식지 선택 기준이 확실한 반면, 비교적 도시 생태계에 잘 적응하고 있는 박새의 경우 서식지 선 택시 산림패치의 속성 및 연결성 이외에 다른 변수 가 고려될 필요가 있음을 보여준다. 즉, 향후 박새 의 서식지 분포를 분석하기 위해서는 녹지패치의 면적뿐만 아니라 곤충 밀도, 서식지 다양성 등과 같 은 질적 평가 요소(홍석환과 곽정인, 2011), 주변 토 지이용정보 등 다양한 환경변수를 추가로 고려할 필요가 있을 것으로 판단된다.

본 연구를 통해 도출된 박새와 쇠박새의 임계거 리는 기존의 연구 결과와 유사한 경향을 보이고 있 다. 특히 스웨덴 남부 참나무 숲을 대상으로 산란된 둥지로부터 이소거리가 수컷의 경우 $510 \mathrm{~m}$, 암컷이 $900 \mathrm{~m}$ 이내라는 연구 결과(Dhondt, 1979), 네덜란 드 낙엽 침엽수림을 대상으로 이소한 박새의 인공 둥지 이용 거리 평균이 암컷 $643 \mathrm{~m}$, 수컷 $498 \mathrm{~m}$ 로 측정된 연구 결과(Dingemanse et al., 2003), 벨 기에의 13 개 산림 패치를 대상으로 박새 확산 거리 를 약 555 725m 정도로 추정한 Matthysen et al.(2005)의 결과와는 매우 유사한 거리임을 확인 할 수 있다. 이러한 기존 연구들은 서울시와 같은 시가화지역을 대상으로 진행된 연구는 아니지만, 본 연구의 결과는 도시지역에서도 박새와 쇠박새의 
서식지 이용에 있어 단절된 녹지 패치간의 거리가 중요하며, 그 임계 거리가 우리나라에서도 $500 \mathrm{~m}$ 정도로 추정될 수 있음을 보여준다. 이러한 결론은 특히 서울시와 같이 극도로 파편화된 도시지역에 수행된 최초의 서식지 연결성 연구로서, 도시지역 에서도 박새와 쇠박새 같은 도시생태계 적응형 산 림성 조류의 서식지 분석을 위해 녹지 패치간 연결 성이 중요하다는 것을 보여준다.

본 연구에서는 녹지 패치간 거리 측정시 직선거 리를 이용하였다(Bunn et al., 2000). 박새류와 같 은 조류는 지상에서 이동하는 포유류 등에 비해 비 교적 토지이용 및 지형의 영향을 덜 받지만, 서울시 와 같이 녹지가 섬 형태로 파편화된 환경에서는 토 지이용 등과 같은 야생동물 이동의 비용거리를 고 려하는 것도 중요하다(송원경 등, 2012). 따라서 도 시지역에서의 연결성 연구는 직선거리를 포함하여 다양한 변수를 고려한 비용거리로 추정하는 연구가 진행될 필요가 있다. 이러한 한계에도 불구하고 본 연구의 결과는 일반적으로 제시되는 징검다리 녹지 의 거리를 제시하였다. 본 연구는 박새와 쇠박새를 대상으로 임계거리를 추정하여 $500 \mathrm{~m}$ 거리를 도출 하였지만, 다른 종을 대상으로 분석할 경우 대상종 의 이동가능성, 행동권에 따라 임계거리는 각각 다 르게 계산될 수 있으므로 대상종 및 대상지 녹지 패 턴 등에 따라 징검다리 녹지 조성을 위한 거리기준 은 달라질 수 있다. 이러한 임계거리 분석 결과는 현재 징검다리 형태로 남아있는 녹지의 중요성 평 가, 향후 녹지 조성을 위한 우선순위 파악 등에 활 용될 수 있을 것으로 판단된다. 또한 도시 생태계에 서 조류의 서식은 녹지구조, 토지이용 등과 밀접한 관계가 있다(곽정인 등, 2010). 따라서 향후 연구에 서는 녹지패치 주변의 토지이용정보를 함께 녹지패 치 특성에 반영할 수 있는 방법을 보완할 필요가 있 다.

\section{$\mathrm{IV}$. 결 론}

서울시와 같이 녹지의 파편화가 심각한 지역에서 는 서식지의 연결성을 확보하는 것이 지속적인 생
태계 관리방안으로서 중요하다. 그러나 종에 따라 파편화 및 단절에 적응하는 수준이 다르기 때문에 적정한 연결성을 확보하는 것은 또 다른 차원의 연 구를 필요로 한다. 본 연구는 도심 녹지에서 서식 가능한 박새류를 대상으로 서식지 특성을 대표하는 3 개 변수와 연결성을 의미하는 3 개 변수를 활용하 여 박새류 분포 현황을 통계모형으로 분석하였다. 단절된 녹지 패치 거리에 따른 박새류 분포 확률을 분석한 결과, 진박새와 곤줄박이는 녹지 패치 거리 변수가 서식지 모형에서 제외된 것은 이 두 종이 산 림내부지역을 선호하는 종이기 때문에 주변 녹지 패치와의 거리가 중요하지 않은 것으로 판단된다. 이와 달리 박새와 쇠박새의 경우 500 800m 수준 의 임계거리 이내의 녹지 패치를 연결지역으로 설 정하는 것이 종 출현을 가장 잘 설명할 수 있음을 확 인하였다. 이 거리는 기존 박새류의 이소거리에 대 한 연구와 유사한 결과로서 서울시 녹지 관리 정책 에 적용하는 것도 가능하다고 판단된다. 이는 서울 시에 분포하고 있는 녹지 중 임계거리 이상으로 단 절된 녹지를 대상으로 징검다리 녹지를 조성한다면 박새와 쇠박새의 서식에 유리한 환경을 제공할 수 있음을 의미한다. 즉, 전략적으로 $500 \mathrm{~m}$ 이상으로 단절된 녹지 패치의 연결성을 향상시키는 공원녹지 정책 수립은 박새와 쇠박새 등과 같은 산림성 조류 의 서식환경을 개선할 수 있다. 그러나 단절된 지역 의 토지이용 및 지형에 따라 이러한 임계거리는 달 라질 수 있으므로 향후 다양한 연결성 측정 방법을 통해 지속적으로 서울시 녹지 패치의 연결성을 확 보 · 증진시키는 노력이 필요하다.

본 연구는 서울시 도시생태현황도 자료를 활용하 여 도시 녹지에 분포하고 있는 산림성 조류인 박새 류의 서식지를 서식지 내·외적 요인으로 분석하여 녹지 연결성 부문의 정량적 연구를 진행하였다는데 의의가 있다. 향후 도시녹지 서식지 연결성 연구에 기여할 수 있을 것으로 판단된다.

향후 연구에서는 서울시의 토지이용, 인간의 간 섭 수준 등에 따른 서식지 질적 요인의 측정변수 적 용 및 연결성 측정 방법을 보다 다양하게 적용한다 면 더욱 효과적인 서식지 단절거리 파악이 가능할 
것으로 판단된다. 본 연구에서는 서울시 행정경계 내부지역만을 연구대상지로 설정하여 북한산 등과 같은 산림지역의 본래 면적, 형태 등이 고려되지 못 한 한계가 있다. 향후에는 연구지역 선정시 유역 등 과 같이 야생동물의 서식환경을 고려하는 방안도 제 안될 수 있을 것이다. 또한 조사자료의 한계로 조류 조사 시기와 토지피복 및 이용도 구축 시기에 차이 가 발생하여 이로 인한 오류를 내포하고 있어 조사 지점별 서식 밀도, 종 수 등 서식 강도에 대한 요인 이 고려되지 못하여 서식지 모형 구축에 한계가 있 다. 향후 기존 자료에 대한 시기별 검토, 서식지 유 형별 중점조사를 통해 서식지 및 야생동물의 질적 이용수준을 정량화하여 모형에 반영한다면 도시생 태계에서 야생동물의 서식지 이용에 대한 보다 다양 한 해석이 가능할 것이라 기대된다. 이와 함께 본 연 구에서는 모형 선택시 통계적 방법인 $\mathrm{AICc}$ 만를 이 용하여 기계적 결과 해석에 머무른 한계가 있다. 향 후 최적 모형 및 이에 준하는 몇 개의 모형에서 선정 된 변수를 중심으로 중점적으로 서식지 모형에 고려 될 수 있는 변수를 추정하는 등과 같은 방법론 개발 이 가능할 것이라 판단된다. 또한 본 연구에서 제안 한 임계거리를 바탕으로 박새와 쇠박새의 서식지 단 절수준을 단계적으로 평가할 수 있는 현장조사 및 현장실험 등을 추가연구로 제안할 수 있다.

\section{사 사}

본 연구는 2012년도 환경부 차세대 에코이노베 이션 기술 개발사업의 지원으로 수행되었으며(과제 번호: 416-111-014), 분석에 사용된 서울시 도시 생태현황도를 제공해주신 서울시와 서울연구원 송 인주 연구위원께 감사드립니다.

\section{참고문헌}

강완모, 박찬열, 2011 , 그래프 이론을 적용한 서울 시 녹지 연결망의 정량적 분석, 한국환경생 태학회지, 25(3), 412-420.

곽정인, 이경재, 한봉호, 2010 , 도시 녹지축 주변
시가화지역 내 야생조류 출현 영향요인 분 석 연구, 한국환경생태학회지, 24(2), 166177.

박찬열, 2011, 번식기 박새류와 곤충과 식물의 상 호작용 네트워크, 서울대학교 대학원 박사 학위논문.

서울특별시, 2010, 2010 도시생태현황도 정비제작 -2 차년도-, 서울특별시.

송원경, 김은영, 이동근, 2012 , 이질적 경관에서의 연결성 측정: 리뷰 및 적용, 환경영향평가, 21(3), 391-407.

원병오, 1981, 한국동식물도감 동물편(조류 생태), 서울: 문교부, 1126 .

이우신, 구태회, 박진영(2000) 야외원색도감 한국 의 새. 서울: LG상록재단. pp. 250-253.

이우신, 박찬열, 임신재, 허위행, 정옥식, 최창용, 박용수, 이은재, 2010, 야생동물생태관리 학, 서울: 라이프사이언스, 331.

임신재, 손승훈, 김규중, 2011, 활엽수림에 설치한 인공새집을 이용한 박새류 번식 생태, 한국 임학회지, 100(3), 397-401.

임신재, 손승훈, 김민진, 강정훈, 2008 , 침엽수림 과 활엽수림 지역에서 박새류의 인공새집 이용, 한국임학회지, 97(1), 83-87.

홍석환, 곽정인, 2011 , 한국산 박새과 조류의 도시 림 식생유형별 출현 특성, 한국환경생태학 회지, 25(5), 760-766.

Amano, T., Y. Kusumoto, Y. Tokuoka, S. Yamada, E.-Y. Kim, S. Yamamoto, 2008, Spatial and temporal variations in the use of rice-paddy dominated landscapes by birds in Japan, Biological Conservation, 141(6), 1704-1716.

Andreu, J., E. Barba, 2006, Breeding dispersal of Great Tits Parus major in a homogeneous habitat: effects of sex, age, and mating status, ARDEA, 94(1), 45-58.

Angold, P. G., J. P. Sadler, M. O. Hill, A. Pullin, S. Rushton, K. Austin, E. Small, B. Wood, 
R. Wadsworth, R. Sanderson, K. Thompson, 2006, Biodiversity in urban habitat patches. The Science of the total environment, 360, 196-204.

Brotons, L., W. Thuiller, M. B. Arau'jo, A. H. Hirzel, 2004, Presence-absence versus presence-only modelling methods for predicting bird habitat suitability, Ecography, 27, 437-448.

Bunn, A. G., D. L. Urban, T. H. Keitt, 2000, Landscape connectivity: A conservation application of graph theory, Journal of environmental management, 59(4), 265278.

Collinge, S. K., T. M. Palmer, 2002, The influences of patch shape and boundary contrast on insect response to fragmentation in California grasslands, Landscape Ecology, 17, 647-656.

Dhondt, A. A., 1979, Summer Dispersal and Survival of Juvenile Great Tits in Southern Sweden, Oecologia, 42, 139157.

Dingemanse, N. J., C. Both, A. J. van Noordwijk, A. L. Rutten, P. J. Drent, 2003, Natal dispersal and personalities in great tits (Parus major). Proceedings, Biological sciences / The Royal Society, 270(1516), 741-7.

Ferraz, G., J. D. Nichols, J. E. Hines, P. C. Stouffer, R. O. Bierregaard, Jr., T. E. Lovejoy, 2007, A large-scale deforestation experiment: effects of patch area and isolation on Amazon birds, Science, 315, 238-241.

Forman, R. T. T., 1995, Some general principles of landscape and regional ecology, Landscape Ecology, 10(3), 133-142.

Forman R. T. T., M. Godron, 1986, Landscape ecology, New York: John Wiley \& Sons.

Freeman, L. C., 1979, Centrality in Social Networks Conceptual Clarification, Social Networks, 1, 215-239.

Hanski, I., 1998, Metapopulation dynamics, Nature, 396, 41-49.

Hanski, I., 1999, Habitat connectivity, habitat continuity, and metapopulations in dynamic landscapes, Oikos, 87(2), 209219.

Jordan, F., A. Baldi, K.-M. Orci, I. Racz, Z. Varga, 2003, Characterizing the importance of habitat patches and corridors in maintaining the landscape connectivity of a Pholidoptera transsylvanica (Orthoptera) metapopulation, Landscape Ecology, 18, 83-92.

Krebs, C. J., 1972, Ecology: the experimental analysis of distribution and abundance, Harper \& Row, New York

Levins, R., 1969, Some demographic and genetic consequences of environmental heterogeneity for biological control, Bull. Entom. Soc. Amer., 15, 237-240.

Luque, S., S. Saura, M.-J. Fortin, 2012, Landscape connectivity analysis for conservation: insights from combining new methods with ecological and genetic data, Landscape Ecology, 27(2), 153-157.

Matthysen, E., T. Van de Casteele, F. Adriaensen, 2005, Do sibling tits (Parus major, P. caeruleus) disperse over similar distances and in similar directions? Oecologia, 143(2), 301-7.

Minor, E. S., D. L. Urban, 2007, Graph theory as a proxy for spatially explicit population models in conservation planning, Ecological Applications, 17(6), 1771-1782.

R Development Core Team, 2012, R: A language and environment for statistical 
computing, R Foundation for Statistical Computing, Vienna, Austria.

Saura, S., L. Pascual-Hortal, 2007, A new habitat availability index to integrate connectivity in landscape conservation planning: Comparison with existing indices and application to a case study, Landscape and Urban Planning, 83(2-3), 91-103.

Taylor, P. D., L. Fahrig, K. Henein, G. Merriam, 1993, Connectivity is a element of landscape structure, Oikos 68(3), 571-573.
Tischendorf, L., L. Fahrig, 2000, How should we measure landscape connectivity? Landscape Ecology, 15, 633-641.

Turner, M. G., 1989, Landscape ecology: the effect of pattern on process. Annual review of ecology and systematics, Vol. 20, 171-197.

Turner, M. G., 2005, Landscape ecology: What is the state of the science? Annu. Rev. Ecol. Evol. Syst., 36, 319-344.

Verhulst, S., C. M. Perrins, R. Riddington, 1997, Natal dispersal of great tits in a patchy environment, Ecology, 78(3), 864-872.

최종원고채택 13.05. 07 